\title{
A 24 hour plastic envelope method for isolating and identifying Gardnerella vaginalis (PEM-GVA)
}

\author{
LETA Q CHING, ${ }^{*}$ KENNETH A BORCHARDT,${ }^{*}$ RODNEY F SMITH, $\dagger$ \\ CHARLES B BEAL $\ddagger$ \\ From the *Center for Advanced Medical Technology, San Francisco State University, San Francisco, the \\ $\dagger$ Contra Costa County Health Department, Martinez, and $\ddagger$ International Health Services, East Palo Alto, \\ California, USA
}

SUMMARY A new plastic envelope culture test that is selective for Gardnerella vaginalis was compared with a conventional method. Vaginal specimens from 92 women were cultured. Results from both methods were compared with the results of pelvic examinations and clinic screening tests used to diagnose bacterial vaginosis (BV). $G$ vaginalis was isolated more often in the envelope than by the conventional method from patients with BV and those without, though the difference was not significant. Isolation and identification of $G$ vaginalis was completed in 18-24 hours by the envelope method; the conventional method took a mean of 72 hours (range two to six days). Polymorphonuclear leucocytes (PMNLs) occurred significantly more in specimens from the patients without BV than from those with BV. Both clue cells and a positive amine test reaction were found significantly more in specimens from patients with BV than from those without BV. Clue cells and $G$ vaginalis isolation correlated best with BV (in 47 women), followed by clue cells and positive amine test results (in 39). Adherence of $G$ vaginalis in the envelope also correlated more with BV, clue cells, and positive amine test results (32) than with patients without BV (14). When there were no clue cells and amine test results were negative the results correlated totally with a prediction of no BV. The use of the rapid envelope culture test would have confirmed BV in $20 \%$ of the cases where clue cell and amine test results were discordant.

Gardnerella vaginalis is considered to be part of the normal human vaginal flora. ${ }^{2}$ In bacterial vaginosis (BV), there is an increased growth of $G$ vaginalis and certain anaerobes, and a decrease in lactobacilli. ${ }^{3-6}$ It has been postulated that $\mathrm{BV}$ is the result of a synergistic relation between the increased flora. ${ }^{6-9}$

The isolation of $G$ vaginalis in diagnosing BV has been controversial. Most isolation and identification methods do not distinguish $G$ vaginalis from other closely related morphotypes. ${ }^{10-12}$ The genus Mobiluncus contains vaginal species that are difficult to isolate and identify ${ }^{13}$ and are present in the normal vagina. ${ }^{14} \mathrm{~A}$ report indicating that bacteria of the genus Mobiluncus either cause BV, or are a more accurate indicator of it than $G$ vaginalis, has further contributed to the controversy. ${ }^{\text {is }}$ Tests for diagnosing BV without isolat-

Address for reprints: Professor K A Borchardt, Department of Clinical Microbiology, Center for Advanced Medical Technology, San Francisco State University, 1600 Holloway Avenue, San Francisco, California 94132, USA

Accepted for publication 9 October 1987 ing $G$ vaginalis, such as the amine test, $\mathrm{pH}$ (CAP (College of American Pathologists) test), and microscopy to find clue cells, have low predictive values for a diagnosis of BV. ${ }^{7617}$

The development of an inexpensive rapid method of isolating and identifying $G$ vaginalis is required to continue the study of its role in BV. The purpose of the study reported here was to evaluate whether the plastic envelope method for $G$ vaginalis (PEM-GVA) could provide a 24 hour diagnostic test for $G$ vaginalis.

\section{Patients, materials, and methods}

\section{STUDY POPULATION}

We examined for BV 111 consecutive women attending the San Francisco State University student health centre. We excluded 19 because of either incomplete information or prior antibiotic treatment. Vaginal discharge was evident in 53 of the remaining 92 patients. Sexual activity was acknowledged in 85 of the women. All patients were examined by one clinician who recorded the patient's history and the results of pelvic examination. 
A vaginal specimen was obtained from each patient, and the following observations were recorded: consistency; colour; $\mathrm{pH}$ (measured with Hydrion Micro $\mathrm{pH}$ paper); wet mount microscopic observation of trichomonads, lactobacilli, red, and white cells and of epithelial cells and clue cells ${ }^{7}$; and the presence or absence of the fishy odour of amines after the addition of $10 \%$ potassium hydroxide. The specimen was then examined under a cover slip for fungal elements.

A specimen was given one point for each of the following variables: consistency (watery or homogeneous), a pH of 4.5 or more, fishy amine odour, and the presence of clue cells. A patient was considered to have BV when her specimen gained three or more points.

\section{CLINICAL METHODS}

The vaginal vault was swabbed simultaneously with two cotton tipped applicators. One was placed immediately in Stuart's transport medium and maintained at room temperature for later routine culture in the laboratory. The second swab was used to inoculate the PEM-GVA system, which was maintained at $35^{\circ} \mathrm{C}$. Both were transported to the laboratory within six hours.

The routine culture swab was used to inoculate a peptone starch dextrose (with $5 \%$ human blood), starch, and bile esculin agar plates. The swab was then smeared on a slide for Gram staining. The plates were incubated in 5-10\% carbon dioxide and examined daily for 72 hours. Growth in the inoculum area was categorised as "rare" (few colonies), "light" (growth in the first quadrant), "moderate" (growth in the second and third quadrants) or "heavy" (growth in the third to fourth quadrants). Colonies that were $\beta$ haemolytic, starch positive, and resembled $G$ vaginalis morphologically on Gram staining were evaluated by the following eight tests: catalase; oxidase; $\alpha$ glucosidase and $\beta$ glucosidase; rapid hippurate; and fermentation of dextrose, maltose, and raffinose. $G$ vaginalis was identified and differentiated from other common isolates by the biochemical characteristics listed in table 1.

Table 1 Reactions of organisms in the PEM-GVA (plastic envelope method of identifying Gardnerella vaginalis) biochemical panel after incubation for two hours at $35^{\circ} \mathrm{C}$

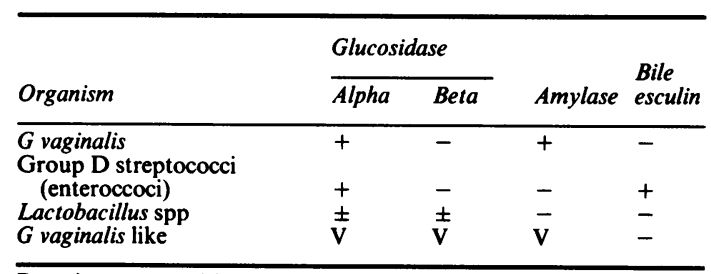

Reactions: +, positive; -, negative; \pm , weak; V, variable.

\section{MEDIA}

Chocolate and bile esculin agar plates were prepared by a standard method. ${ }^{18}$ Peptone starch dextrose agar plates were prepared with either $5 \%$ human blood or $2 \%$ soluble corn starch. ${ }^{19}$ The PEM-GVA selective medium (International Health Services, Palo Alto, California, USA) was an enriched proteose peptone broth with a combination of the following antibiotics to control the growth of the polymicrobial flora introduced with the vaginal specimen: an aminoglycoside, a sulphonamide, a peptide, and an antifungal agent. It produced concentrations of $G$ vaginalis of $1 \times 10^{7} \mathrm{ml}$ to $1 \times 10^{9} \mathrm{ml}$ within 24 hours. At $5^{\circ} \mathrm{C}$ the medium had a shelf life of three months.

\section{BIOCHEMICAL TESTS}

The presence of $G$ vaginalis was confirmed using standard biochemical tests. Greenwood's method was used to detect acid from dextrose, maltose, and raffinose. ${ }^{20}$ The hippurate test was that of Piot et al..$^{12}$ The Pantrek amylase assay (Calbiochem-Behring) was used for the rapid amylase test. A rapid bile esculin test used the method of MacFaddin. ${ }^{21}$ Catalase and oxidase tests were performed on colonies obtained from either 48 or 72 hour plate cultures on peptone dextrose agar with $2 \%$ soluble corn starch. ${ }^{20}$

\section{GRAM STAIN}

Gram stained smears of the clinical specimens were viewed under oil immersion at $1000 \times$ magnification for both bacteria and white blood cells (polymorphonuclear leucocytes (PMNLs), which were recorded as follows: rare (fewer than one a field), few ( $1-5$ a field), several (6-30 a field), and numerous (more than 30 a field). Epithelial and clue cells were counted at $100 \times$ magnification using the same criteria.

\section{USE OF THE PEM-GVA SYSTEM}

The envelope was opened (fig 1), and the medium was inoculated with the specimen by placing the swab in the medium and rotating it once before discarding it. This manoeuvre prevented overinoculation of the medium and potential excess growth by contaminants. The carbon dioxide generator compartment was then activated, and the envelope was hung vertically and incubated at $35^{\circ} \mathrm{C}$ for a minimum of 18 hours. After 18 hours an aliquot of the sediment was subcultured on both human blood agar and starch agar plates to assess bacterial growth and identify colonies morphologically resembling $G$ vaginalis (fig 2). Clumps of organisms in the sediment were classified as follows by the number of adherent rods observed: $4+(24$ or more); $3+(15-20) ; 2+(10-14)$; and 1 + (2-9).

A clue cell was defined as a vaginal epithelial cell whose border could not be traced because it was entirely obscured by bacteria. ${ }^{12}$ 


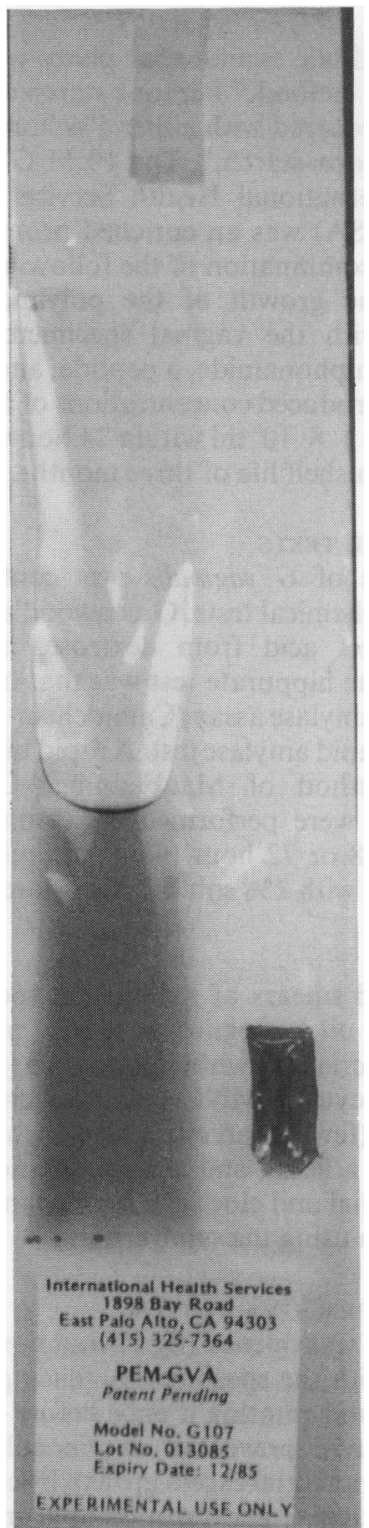

Fig 1 A PEM-GVA (plastic envelope method for Gardnerella vaginalis) test shown after inoculation of specimen and incubation for 18 hours at $35^{\circ} \mathrm{C}$ (carbon dioxide generator shown in bottom right corner of envelope).

Additional sediment was used for the following tests: $\alpha$ glucosidase and $\beta$ glucosidase, amylase, and rapid bile esculin. The tests were read at one and two hours.

\section{Results}

We examined and evaluated 92 women in this study

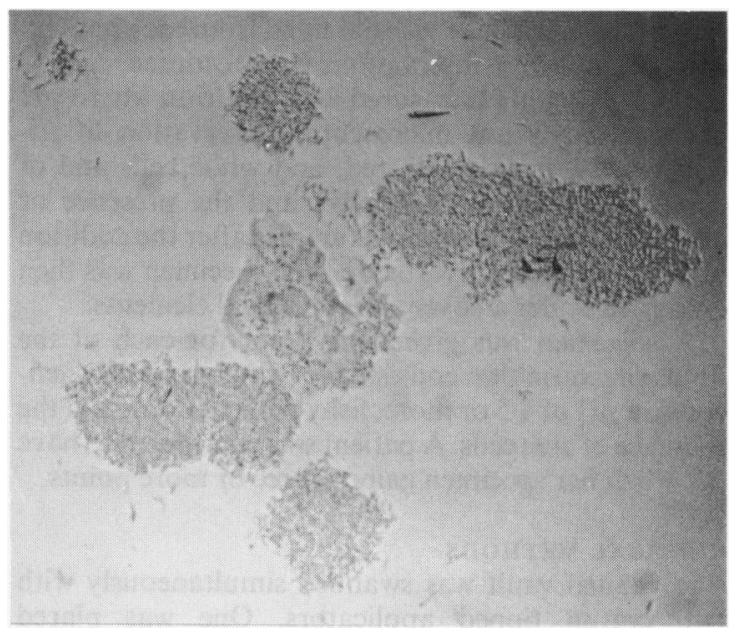

Fig 2 Sediment from a positive PEM-GVA test showing autoclumping.

(table 2). Based on the results of their pelvic examination and screening tests, 43 were diagnosed as not having BV (with scores of 2.0 or less) and 49 were diagnosed as having BV (with scores of 3.0 or more). Saline and potassium hydroxide wet mounts detected trichomoniasis and candidiasis in nine of the 43 without BV and six of the 49 with BV. Raised $\mathrm{pH}$ was found in three patients without and eight with BV. The amine sniff test results were positive in four patients without and 41 with BV ( $p<0.05)$. In contrast, several to numerous PMNLs were detected in 22 patients without BV and 13 with BV $(p<0.05)$. None of the patients without BV had positive results for both clue cells and the amine sniff test. In contrast, 39 patients with BV had positive results for both of these tests.

$G$ vaginalis was isolated from the PEM system in 19 patients without BV and 47 with BV. With conventional procedures, $G$ vaginalis was isolated from 13

Table 2 Comparison of patients with bacterial vaginosis (BV) and those without $B V$

\begin{tabular}{|c|c|c|}
\hline & $\begin{array}{l}\text { No with } B V \\
(n=49)\end{array}$ & $\begin{array}{l}\text { No without } B V \\
(n=43)\end{array}$ \\
\hline $\begin{array}{l}\text { Positive pelvic examination and } \\
\text { score of } 3 \text { or more on } \\
\text { screening tests }\end{array}$ & 49 & 0 \\
\hline Positive for either Trichomonas & & \\
\hline vaginalis or Candida albicans & 6 & 9 \\
\hline Raised pH & 8 & 3 \\
\hline $\begin{array}{l}\text { Positive amine sniff test reaction } \\
\text { Several to numerous }\end{array}$ & 41 & 4 \\
\hline $\begin{array}{l}\text { pelymorphonuclear } \\
\text { poucocytes }\end{array}$ & 13 & 22 \\
\hline $\begin{array}{l}\text { Positive clue cell and amine sniff } \\
\text { test results }\end{array}$ & 39 & 0 \\
\hline
\end{tabular}


without BV and 45 with BV. The differences in isolation of the organism by PEM compared with conventional methods in each patient group were not significant $\left(\chi^{2}=1 \cdot 56\right)$. The average time required by conventional isolation procedures and methods of identifying $G$ vaginalis was 72 hours (range two to six days) whereas the PEM method required only 18 to 24 hours for both isolation and definitive identification.

The adhesive density of $G$ vaginalis after 18 hours' growth in PEM (fig 2) ranged from $2+$ to $4+$, and was found in 32 patients with BV and 14 without $B V(p<$ $0 \cdot 05$ ). Of the 14 with clumping but no $B V$, only five had clue cells in their discharge specimen, none were amine sniff test positive, and only one had a raised $\mathrm{pH}$.

\section{Discussion}

In this study, fewer PMNLs in patients with BV than those without BV was consistent with the criteria for defining BV. ${ }^{7}$ Marquez-Davila and Martinez-Barreda found that when clue cell and amine tests both gave negative results, the negative predictive value for BV was $99 \% .{ }^{17}$ Our results support their observations, but differ from theirs over the positive predictive value for BV when both clue cell and amine test results are positive. In our study $39(80 \%)$ of the women with BV had positive results in both tests and yielded $G$ vaginalis, whereas Marquez-Davila and MartinezBarreda reported that the positive predictive value for both clue and amine tests was only $45 \% .{ }^{17}$

The PEM was slightly, but not significantly, more sensitive than the conventional method for detecting $G$ vaginalis. Because the role of $G$ vaginalis as either the cause or indicator of BV is debatable, the improved method for isolating and identifying $G$ vaginalis could add to the confusion of diagnosis. Because combined positive results of clue cell and amine tests detect $80 \%$ of women with BV, however, the PEM system could improve diagnosis for $20 \%$ or perhaps more of women with BV when either the clue cell or amine test give negative results. ${ }^{17}$

The PEM system may be of value in clinic screening for BV. Compared with routine methods, the PEM system had the advantage of rapid isolation and specific identification of $G$ vaginalis with suppression of vaginal contaminants, and was conveniently performed in two hours, including the $\alpha$ glucosidase and $\beta$ glucosidase assays. These are important for differentiating $G$ vaginalis from closely related morphotypes." The system is compact for storage, disposable, and stable for three months at $5^{\circ} \mathrm{C}$.

The adherence density of $G$ vaginalis in the PEM broth from patients with BV was observed microscopically by evaluating the broth after incubation for 18 hours. As this observation had not been reported previously in broth, clumps of the bacteria were arbitrarily classified as $1+$ to $4+$, depending on the numbers of organisms in the aggregates. This may be an indirect measure of the number of organisms in the specimen or may be caused by some adherence factor produced by $G$ vaginalis that affects primary growth in vitro, or both. Adherence of organisms occurred in 43 of the 47 patients with BV who had clue cells and yielded $G$ vaginalis by PEM culture. This adhesiveness may indicate a possible role in the pathogenesis of BV. ${ }^{22}$ Additional studies are required to evaluate adherence in association with BV and its importance as an identification feature.

We thank Dr William Bigler, for editorial suggestions, James P Jackson, for manuscript consultation, and Joseph Mahood for technical help.

\section{References}

1 Taylor E, Blackwell AL, Barlow D, Phillips I. Gardnerella vaginalis, anaerobes, and vaginal discharge. Lancet 1982;i:1376-9.

2 Taskhkjian JH, Coullam CB, Washington JA. Vaginal flora in asymptomatic women. Mayo Clin Proc 1976;51:557-61.

3 Corbishley CM. Microbial flora of the vagina and cervix. J Clin Pathol 1977;30:745-8.

4 Shafer MA, Sweet AL, Ohm-Smith MJ, Shalwitz J, Beck A, Schachter J. Microbiology of the lower genital tract in postmenarchal adolescent girls: differences by sexual activity, contraception, and presence of nonspecific vaginitis. $J$ Pediatrics 1985;107:974-81.

5 Spiegel CA, Eschenbach DA, Ansel R, Holmes KK. Curved anaerobic bacteria in bacterial (nonspecific) vaginosis and their response to antimicrobial therapy. J Infect Dis 1983;148: 817-22.

6 Tabaqchali S, Wilks M, Thin RN. Gardnerella vaginalis and anaerobic bacteria in genital disease. British Journal of Venereal Diseases 1983;59:111-5.

7 Blackwell A, Barlow D. Clinic diagnosis of anaerobic vaginosis (non-specific vaginitis). British Journal of Venereal Diseases 1982;58:387-93.

8 Levison ME, Trestman I, Quach E, Sladowski C, Flora CN. Quantitative bacteriology of the vaginal flora in vaginitis. Am J Obstet Gynecol 1979;133:139-41.

9 Spiegel CA, Ansel R, Eschenbach DA, Schoenknecht F, Holmes $\mathrm{KK}$. Anaerobic bacteria in nonspecific vaginitis. $N$ Engl J Med 1980;303:601-71.

10 Bailey RK, Voss JL, Smith RF. Factors affecting isolation and identification of Haemophilus vaginalis. J Clin Microbiol 1979;9:65-71.

11 Piot P, Van Dyck E, Goodfellow M, Falkow S. A taxonomic study of Gardnerella vaginalis (Haemophilus vaginalis) Gardner and Dukes 1955. J Gen Microbiol 1980;119:373-96.

12 Piot P, Van Dyck E, Totten PA, Holmes KK. Identification of Gardnerella (Haemophilus) vaginalis. J Clin Microbiol 1982;15:19-24.

13 Roberts MC, Hillier SL, Schoenknecht FD, Holmes KK. Nitrocelluose filter blots for species identification of Mobiluncus curtisii and Mobiluncus mulieris. J Clin Microbiol 1984;20: 826-7.

14 Roberts MC, Hillier SL, Schoenknecht FD, Holmes KK. Comparison of Gram stain, DNA probe, and culture for the identification of species of Mobiluncus in female genital specimens. J Infect Dis 1985;152:74-7.

15 Thomason JL, Schreckenberger PC, Spellacy WN, Riff LJ, LeBeau LJ. Clinical and microbiological characterization of 
patients with nonspecific vaginosis associated with motile, curved anaerobic rods. $J$ Infect Dis 1984;149:801-9.

16 Bump RC, Zuspen FP, Buesching III WJ, Ayers LW, Stephens TJ The prevalence, six-month persistence, and predictive values of laboratory indicators of bacterial vaginosis (non-specific vaginitis) in asymptomatic women. Am J Obstet Gynecol 1984;150:917-24.

17 Marquez-Davila G, Martinez-Barreda CE. Predictive value of the "clue cells" investigation and the amine volatilization test in vaginal infections caused by Gardnerella vaginalis. J Clin Microbiol 1985;22:686-7.

18 Rohde PA. BBL Manual of Products and Laboratory Procedures. 5th ed. Cockeysville, Maryland, USA: Baltimore Biological Laboratories, 1973:112.

19 Dunkelberg W, Skeggs E, Kellogg DS. Method for isolation and identification of Corynebacterium vaginale (Haemophilus vaginalis). Applied Microbiology 1970;19:47-52.

20 Greenwood JR, Pickett MJ. Salient features of Haemophilus vaginalis. J Clin Microbiol 1979;9:200-4.

21 MacFaddin JF. Biochemical tests for identification of medical bacteria. Ist ed. Baltimore: Williams \& Wilkins, 1977:9.

22 Scott TG, Smyth CJ, Keane CT. In vitro adhesiveness and biotype of Gardnerella vaginalis strains in relation to the occurrence of clue cells in vaginal discharges. Genitourin Med 1987;63:47-53. 